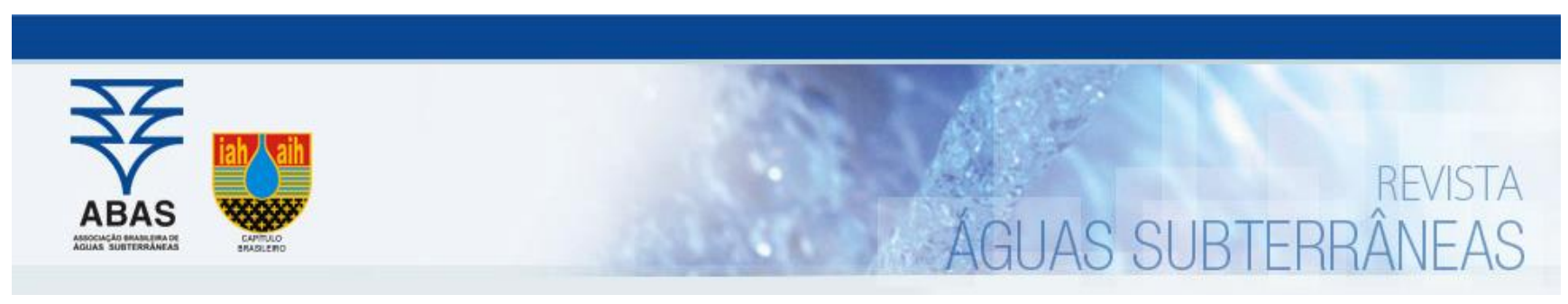

Artigos

\title{
Balanço hídrico em sistema hidrogeológico cárstico, região de Lagoa Santa, Minas Gerais
}

\section{Water balance in karstic hidrogeologic system, region of Lagoa Santa, Minas Gerais}

\author{
Rodrigo Sergio Paula1; Leila Nunes Menegasse Velásquez ${ }^{1}$ \\ 1 Universidade Federal de Minas Gerais (UFMG), Belo Horizonte, MG, Brasil. \\ $\square$ rodrigo.spdm@yahoo.com.br, menegase@yahoo.com.br
}

\begin{tabular}{|c|c|}
\hline & Resumo \\
\hline $\begin{array}{l}\text { Palavras-chave: } \\
\text { APA Lagoa Santa. } \\
\text { Balanço Hídrico. } \\
\text { Cárstico-fissurais. } \\
\text { Recarga. }\end{array}$ & $\begin{array}{l}\text { A área estudada, APA Carste de Lagoa Santa e seus entornos, localiza-se a } 35 \mathrm{~km} \text { norte de Belo Horizonte abrange } \\
\text { cerca de } 505 \mathrm{~km}^{2} \text {. A região tem sido alvo de vários empreendimentos que prever um aumento pela demanda de água, } \\
\text { diante deste crescimento e da fragilidade do sistema carste é imprescindível o conhecimento do sistema hidrológico, } \\
\text { tal como a compreensão balanço hídrico. Geologicamente, a região é representada por metacalcárias e metapelíticas } \\
\text { neoproterozoicas do Grupo Bambuí, com rica densidade de feições de dissolução cársticas que favorecem a recarga } \\
\text { e a condução rápida da água. As drenagens da região são afluentes pela margem esquerda do rio das Velhas que } \\
\text { funciona como nível de base. O objetivo do trabalho foi realizar o balanço hídrico, com ênfase na recarga aquífera, } \\
\text { atentando para a complexa rede de drenagem subterrânea com entradas e saídas do sistema. Informações disponíveis } \\
\text { sobre conexões hídricas auxiliaram no modelo de circulação adotado para equacionamento do balanço hídrico. Foram } \\
\text { instaladas } 6 \text { estações fluviométricas em } 6 \text { bacias, monitoradas no ano hidrológico } 2016 / 2017 \text {, cujos dados foram } \\
\text { empregados no cálculo da recarga aplicando a metodologia de Rutledge e Daniel (1994). O escoamento de base médio } \\
\text { das bacias de } 91 \% \text { do total confirma a importância da água subterrânea para o sistema hidrológico e a recarga de } \\
12 \% \text { da precipitação anual (1010 mm) pode ser adotada como valor mínimo por haver ainda outras saídas hídricas } \\
\text { não contempladas no trabalho. }\end{array}$ \\
\hline
\end{tabular}

Abstract

Keywords:

APA Lagoa Santa.

Karstic-fissural.

Water Balance.

Aquifer Recharge.

Revisado por pares.

Recebido em: 14/11/2018.

Aprovado em: 07/03/2019.

\begin{abstract}
The studied area, APA Lagoa Santa Karst and its surroundings, is located $35 \mathrm{~km}$ north from Belo Horizonte and it covers around $505 \mathrm{~km}^{2}$. The region has been a target to many enterprises that demand an increase on water request. Having as a scenario this growth and the fragility of the Karst system, it becomes necessary to know the hydrological system, as well as to understand the hydric balance. Geologically, the area is represented by metacalcarium and neoproterozoic metapelitic rocks from The Bambuí Group, with rich density of features of karstic dissolution that make the recharge and the fast conduction of the flows water. The drainage of the region is affluent by the left bank of Das Velhas river that functions as its base level. The objective of this project was to perform the water balance, with emphasis on the aquifer recharge, considering the complex underground drainage network with inputs and outputs of the system. Available information about hydric connections have helped on the adopted circulation model used to equate hydric balance. 6 fluviometric stations were installed in 6 basins, having monitored the hydrological year of 2016/2017, whose data was used to calculate its recharge using the methodology of Rutledge and Daniel (1994). The average flow of the basin in $91 \%$ of the total confirms the importance of underground water to the hydrological system and the recharge of $12 \%$ of the annual precipitation $(1010 \mathrm{~mm})$ can be adopted as minimum value, once there are other hydric outputs that are not analysed in this work.
\end{abstract}

DOI: http:/dx.doi.org/10.14295/ras.v33i2.29252

\section{INTRODUÇÃO}

A área considerada, de aproximadamente $505 \mathrm{~km}^{2}$, engloba totalmente a região da APA - Carste de Lagoa Santa, alcançando uma área de proteção ambiental de aproximadamente $350 \mathrm{~km}^{2}$. A região da APA definida pelo conjunto paisagístico e cultural, composto por um sistema de cavernas e demais formações cársticas, sítios arqueopaleontológicos, com cobertura vegetal e fauna silvestre, cuja preservação é fundamental para o ecossistema da região (VIANA, 1998).
O balanço hídrico em qualquer região resulta nos quantitativos de entrada e saída. Segundo Tucci (2002), é uma aplicação da equação da continuidade de massa em uma região. Em regiões cársticas, além do monitoramento climático e fluvial, é preciso conhecer as principais rotas de fluxo de água subterrânea. Goldscheider \& Drew (2007) afirma que o fluxo subterrâneo em áreas cársticas é muitas vezes independente da topografia, embora geralmente guiado por formações geológicas e estruturais. Portanto, os compartimentos hidrogeológico não necessariamente coincidem com as bacias hidrográficas. 
Em termos de recarga, as águas pluviais podem chegar aos sistemas cársticos de quatro maneiras: recarga alogênica, infiltração difusa, escoamento interno e por aquíferos suspensos. Já a descarga, a água retorna à superfície geralmente através de grandes surgências (WHITE, 2002).

Portanto, torna-se necessária a identificação da origem das águas subterrâneas nas sub-bacias estudadas para melhor caracterização do balaço hidríco. A interpretação da origem da água subterrânea e sua relação com a bacia aflorante contribui para uma melhor interpretação dos quantitativos de saída e entrada do sistema.

Para melhor aproximação das características do sistema carste (baixo armazenamento e rápidas respostas a eventos pluviométricos), foi adotado o método de Rutledge e Daniel (1994), que o propuseram por meio de uma curva de recessão média representativa de todo o sistema, a qual é gerada a partir de pequenas curvas de recessão, em resposta a eventos de chuva mais próximos. Costa (2005) aplicou, dentre outros métodos, o método citado em aquíferos granulares, encontrando curvas de recessão mais eficientes para esse. Albuquerque (2009) demonstrou a eficiência do método comparando-o com outros aplicados em aquíferos granulares do Grupo Urucuia, obtendo valores de recarga mais precisos do que os métodos tradicionais.
Devido à fragilidade ambiental deste sistema cárstico e uso extensivo dos recursos hídricos, propôs-se quantificar um balanço hídrico para possibilitar a individualização da participação de cada sub-bacia.

O estudo objetivou o equacionamento das entradas e saídas de água do sistema, discretizando os aportes externos, a recarga, as descargas naturais normais e atípicas ao fluxo, e as descargas por bombeamento. Esse balanço hídrico foi comparado com o balanço hídrico climático realizado, pelo método de Thornthwaite e Mather (1955), para se verificar a aplicabilidade desse método clássico, amplamente empregado, nesse tipo de sistema, um carste ativo, bem desenvolvido e interconectado.

\section{CARACTERÍSTICAS FÍSICAS DA ÁREA DE ESTUDO}

A área possui cerca de $505 \mathrm{Km}^{2}$ e dista $35 \mathrm{~km}$ a norte de Belo Horizonte, envolvendo parcial ou integralmente os municípios de Lagoa Santa, Vespasiano, Funilândia, Confins, Matozinhos, Pedro Leopoldo e Prudente de Morais, e engloba por completo a região denominada APA Carste de Lagoa Santa e entornos (Fig. 1).

Figura 1 - Mapa Localização da Área de estudo com destaque para os limites da APA Carste em amarelo

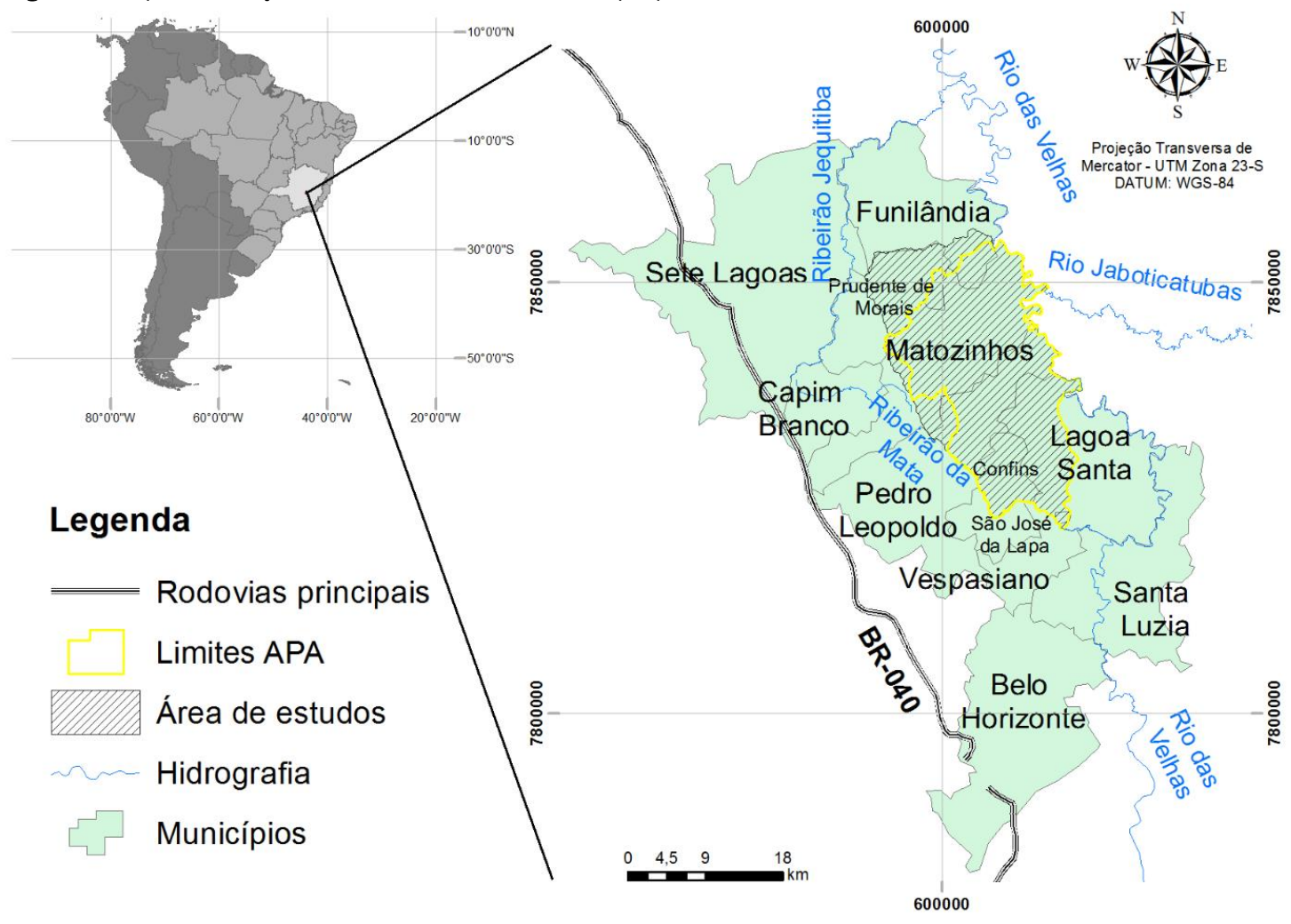


HIDROGRAFIA - A área insere-se na margem esquerda do rio das Velhas, flanqueando-a nas suas porções nordeste e leste, o qual atua como nível de base, com cotas de $630 \mathrm{~m}$ a 660 m. A sudoeste e oeste, a área é balizada pelo Ribeirão da Mata, afluente do rio das Velhas logo a montante da área (Fig. 2). A Tabela 1 exibe as dimensões das bacias, destacando as monitoradas. Seis delas drenam direta ou indiretamente para o rio das Velhas pelos cursos d'água homônimos, os quais são: Palmeira, Jaguara, Escrivânia, Gordura, Jaque e Flor; enquanto o córrego Samambaia imerge em um sumidouro próximo ao rio das Velhas, porém o destino do fluxo é ainda desconhecido.

Figura 2 - Mapa hidrográfico e dos pontos de aquisição dos dados hidrológicos realçando as nascentes de entradas e saídas água da área de estudo

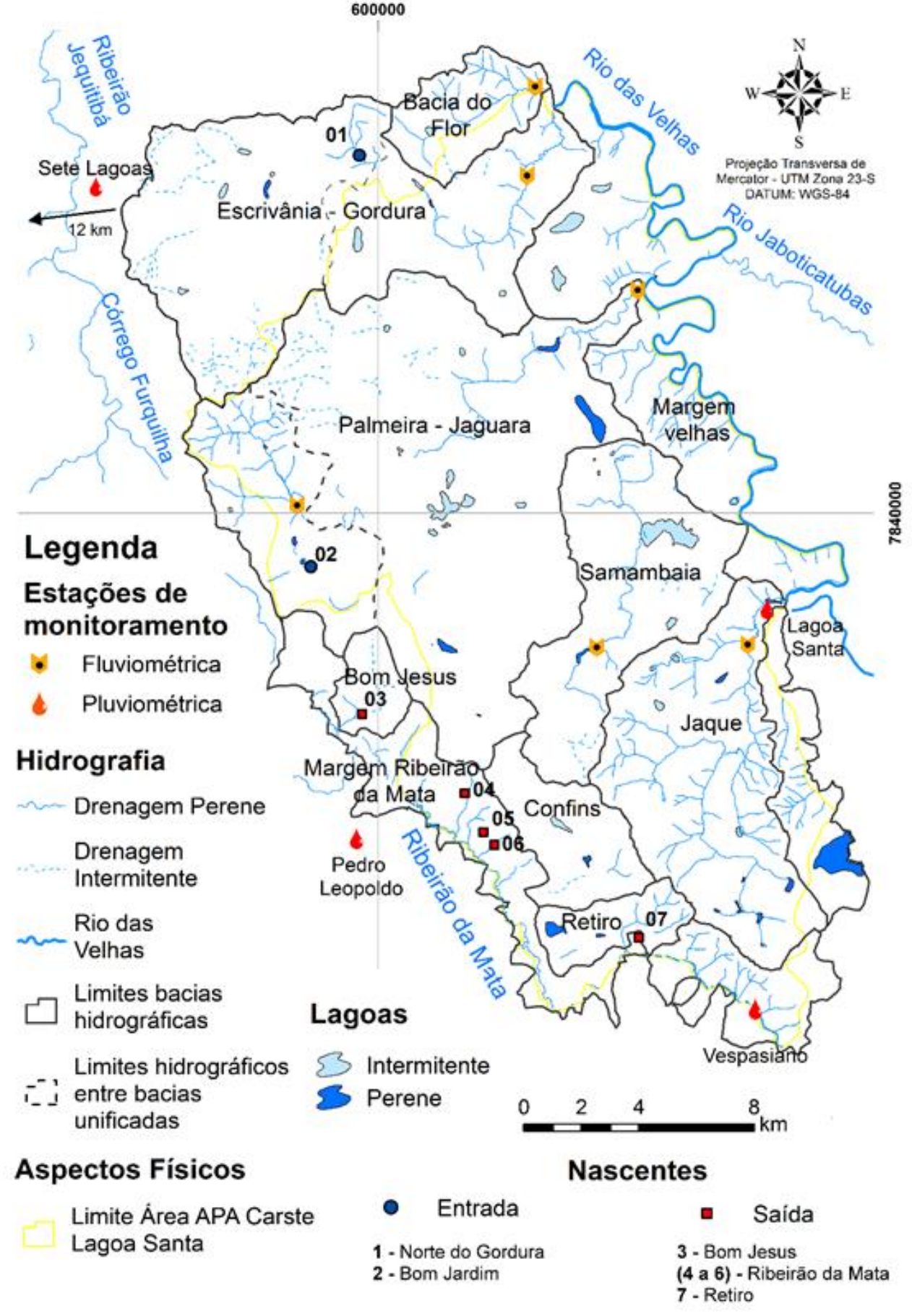

A bacia Escrivânia é completamente fechada e possui apenas uma importante descarga por uma surgência cárstica, que percorre superficialmente $500 \mathrm{~m}$ e ressurge na bacia Gordura, formando assim um compartimento único denominado Escrivânia-Gordura (VELÁSQUEZ et. al., 2018).

Igualmente ocorre com o córrego Palmeira que drena superfi- cialmente numa bacia fechada, recebendo a maior contribuição de uma surgência cárstica na porção baixa da bacia, imergindo em um sumidouro e ressurgindo na bacia Jaguara. Nesta mesma bacia, outro sumidouro drena água da nascente da Lagoa Bom Jardim (2 da Fig. 2), ressurgindo também na bacia Jaguara. Essas conexões formam um compartimento único, denominado de Palmeira-Jaguara (AULER, 1994). 
As demais bacias são, ou completamente fechadas, sem drenagem de imersão conhecida (Confins), ou parcialmente fechadas, drenando através de surgências cársticas diretamente para o Ribeirão da Mata (3 Bom Jesus e 7 Retiro Fig. 2). Ocorrem ainda drenagens marginais diretas para o Velhas e Ribeirão da Mata (4, 5 ,6 da Fig. 2), a maioria em sedimentos de cobertura, mas também ocorrem surgências cársticas caudalosas. Embora ainda sem comprovação, há fortes indícios de que todas as surgências cársticas drenantes para a bacia do Ribeirão da Mata funcionam como pontos de descargas (atípicas) oriundas das porções interiores da área estudada, devendo ser relevadas no balanço hídrico.

À exceção do Jaque e Flor, que drenam parcialmente sobre os metapelitos (Fig. 3), as demais se encontram predominantemente em terreno cárstico e as marginais em sedimentos de coberturas (Tab.1)

Tabela 1 - Características das bacias hidrográficas monitoradas e não monitoradas

\begin{tabular}{|c|c|c|c|}
\hline Bacias & Área $\left(\mathrm{Km}^{2}\right)$ & Comprimento do córrego (Km) & Litologia \\
\hline Bom Jesus * & 7 & 3,5 & Calcário \\
\hline Retiro * & 10 & 4,0 & Calcário \\
\hline Flor & 16 & 5,0 & Pelito - Calcário \\
\hline Confins * & 18 & 0,0 & Calcário \\
\hline Palmeira & 31 & 6,0 & Calcário \\
\hline Margem Rib. da Mata & 38 & -- & Coberturas \\
\hline Gordura & 39 & 14,0 & Calcário \\
\hline Samambaia & 48 & 9,0 & Calcário \\
\hline Escrivânia * & 57 & 0,5 & Calcário \\
\hline Margem Velhas * & 57 & -- & Coberturas \\
\hline Jaque & 59 & 17,0 & Pelito - Calcário \\
\hline Jaguara & 125 & 14,0 & Calcário \\
\hline
\end{tabular}

Em negrito - bacias monitoradas; * bacias não monitoradas

GEOMORFOLOGIA - Á área é formada por terrenos carbonáticos desenvolvidos, com abundância de feições de dissolução como maciços fraturados, sumidouros, dolinas, surgências caudalosas, dutos e cavernas. Conforme Pessoa (2005), as três primeiras representam um indicativo de um sistema cárstico desenvolvido, favorecendo a recarga aquífera pluvial.

GEOLOGIA - A área de estudo abrange, da base para o topo, o Complexo Gnássico-Granítico-Migmatítico Belo Horizonte, sobreposto pelas rochas carbonáticas e siliclásticas da sequência transgressiva-regressiva do Grupo Bambuí, formada pelas
Formações Sete Lagoas e Serra de Santa Helena. O topo da sequência é constituído pelas Coberturas Cenozoicas (Ribeiro et al., 2003) (Fig. 3). Estruturalmente, os contatos entre as unidades se apresentam de forma brusca e discordante, podendo também ocorrer por descolamento basal e com indicadores cinemáticos apontando o movimento reverso. Galvão et al. (2016) sugere, a partir de perfis litológicos de poços, a existência de falhas responsáveis por deslocar as sequências inferiores e as posicionar em contato com sequências superiores nas proximidades da região. 
Figura 3 - Mapa Geológico (adaptado de RIBEIRO et al., 2003) evidenciando as bacias hidrogeológicas detalhadas no trabalho

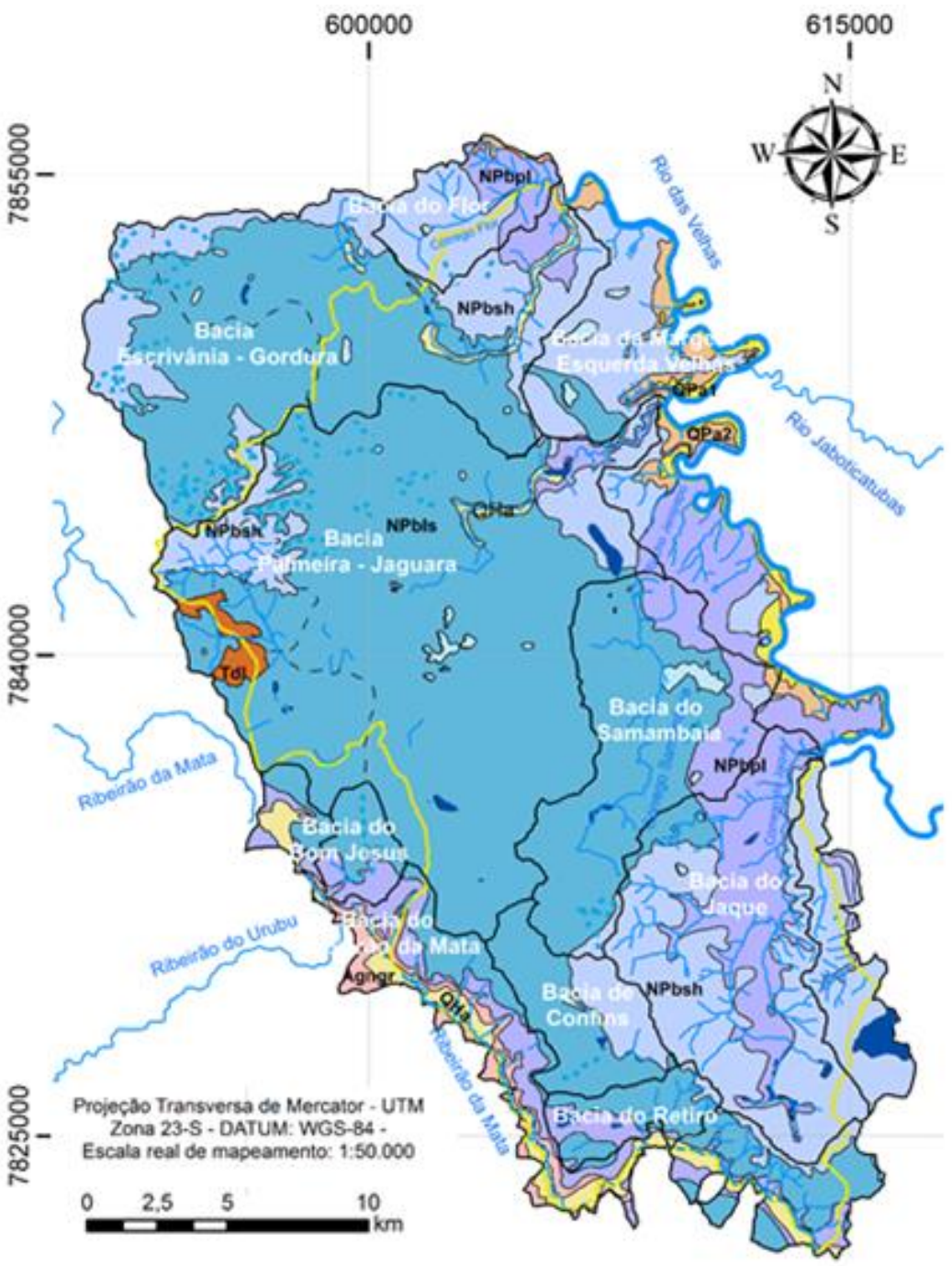

\section{Legenda \\ Hidrografia}

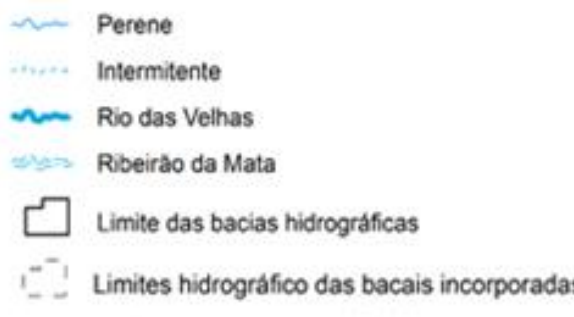

\section{Lagoas - Levantamento 1:25.000}

3 Intermitente

3 Perene

\section{Aspectos Fisicos}

Limite - APA Carste Lagoa Santa

\section{Unidades Litoestratigráficas}

Coberturas Cenozóicas

$\mathrm{OHa}$ Aluviao: cascalho fino a grosso, areia.

fina a grossa, silte e argila

Terraço aluvial: sedimentos areno-arglosos com granulos de quartzo

OPar Terraço aluvial: sedimentos conglomeraticos. arenosos e argilosos inconsolidados

Td Coberturas Detrito-Lateriticas: solo lateritico. areno-argiloso, concrepbes ferruginosas. fragmentos de quartzo

\section{Neoproterozóico}

NPben Fm. Serra de Santa Helena: pelitos, arentos, lentes carbonaticas, margas e calcarenęos finos

NPbls Fm. Sete Lagoas - Membro Lagoa Santa: calcarenitos com intercalaçbes de calcissiltitos, estromatoitios

NPbol Formaça Sete Lagoas - Membro Podro Leopoldo Arqueano calcissittios, calcarenitos finos

Agngr Migmattos, graninoides, gnaisses a hornblenda: biotta gnaisse diopsidio. anfibolio-gnaisse
HIDROGEOLOGIA - Os aquíferos cársticos semi-confinados a livres são predominantes, sendo bastante produtivos e vulneráveis. A conformação desses aquíferos está vinculada à presença dos carbonatos com feições de dissolução como dolinas em superfície e cavernas em profundidade, as quais, de maneira interligada, formam uma rede de dutos e fendas alargados pela ação da água (VIANA,1998).

O embasamento, representado por uma aquífero fissural de baixo potencial, aflora restritamente na borda da bacia, nas porções oeste e sul.

A unidade aquífera formada pela formação Sete Lagoas é constituída pelos calcários impuros de granulometria fina cor cinza claro subordinados a calcarenitos e margas do membro Pedro Leopoldo, e o membro Lagoa Santa, sobreposto, consiste de calcários puros de granulometria grossa e cor mais escura. Perfis de poços tubulares próximos ao rio das Velhas 
mostram espessuras superiores a 300 m desta unidade aquífera, apresentando fluxo predominantemente para o rio das Velhas. Conforme detalho por Velásquez et. al. (2018), o Mb lagoa Santa apresenta o maior potencial hídrico deste aquífero, as principais feições carsticas, maiores permeabilidades e principais zonas de recarga.

A unidade aquífera da formação Serra de Santa Helena encerra os metapelitos intemperizados, formando aquitardos ou localmente aquíferos pobres. Esta unidade geológica e as coberturas cenozoicas podem atuar localmente como zonas de recarga localizada para os aquíferos sotopostos (PESSOA, 2005).

CLIMA - os valores climáticos médios anuais, com base nos anos de 1961 a 1990, da Estação Lagoa Santa, são: Precipitação:1287 mm, Evapotranspriação Real: 996 mm (77\%), Excedente Hídrico: 291 mm (22,6\%) e Deficit: 99 mm (8\%) (VIANA, 1998).

\section{MÉTODOS}

Todos os dados hidrológicos monitorados corresponderam ao ano hidrológico, outubro/2016 a setembro/2017. O estudo foi realizado segundo os métodos detalhados abaixo: i) Monitoramento fluviométrico das bacias (Tab. 1; Fig. 2) por meio de transdutores de pressão, com leitura automática a cada 15 min., nos locais de mais baixo curso possível. As curvas chaves elaboradas seguiram padrão gráfico internacional da relação de variação da cota $(h)$ com a vazão (Q) - h/Q, (FILHO et al., 2001; TUCCl, 2002; PISCOYA et al, 2013).

Com as vazões obtidas, foi possível relacionar estes dados com a área das bacias obtendo as vazões especificas. Em caso das nascentes monitoradas, adotou-se a vazão especifica aparente por ter sido realizado apenas a medida de vazão na máxima estiagem no ano de 2017.

ii) Obtenção da recarga aquífera: foi adotado o método de Rutledge e Daniel (1994), que propuseram o deslocamento dos vários pequenos períodos de recessão do hidrograma, compondo a curva mestra de recessão (CRM - Fig. 4), a partir da qual obteve-se o índice de recessão médio e, consequentemente, a recarga. 0 valor de recarga, tal como os valores de escoamento, terá seu percentual relacionado à pluviometria anual $(\mathrm{P}-1010 \mathrm{~mm})$ da região. Com os dados de escoamento foi realizado a razão entre escoamento subterrâneo e total para obtenção do potencial hídrico e índice de fluxo de base de cada bacia.

Figura 4 - Típica curva de recessão mestra evidenciando as curvas individuais

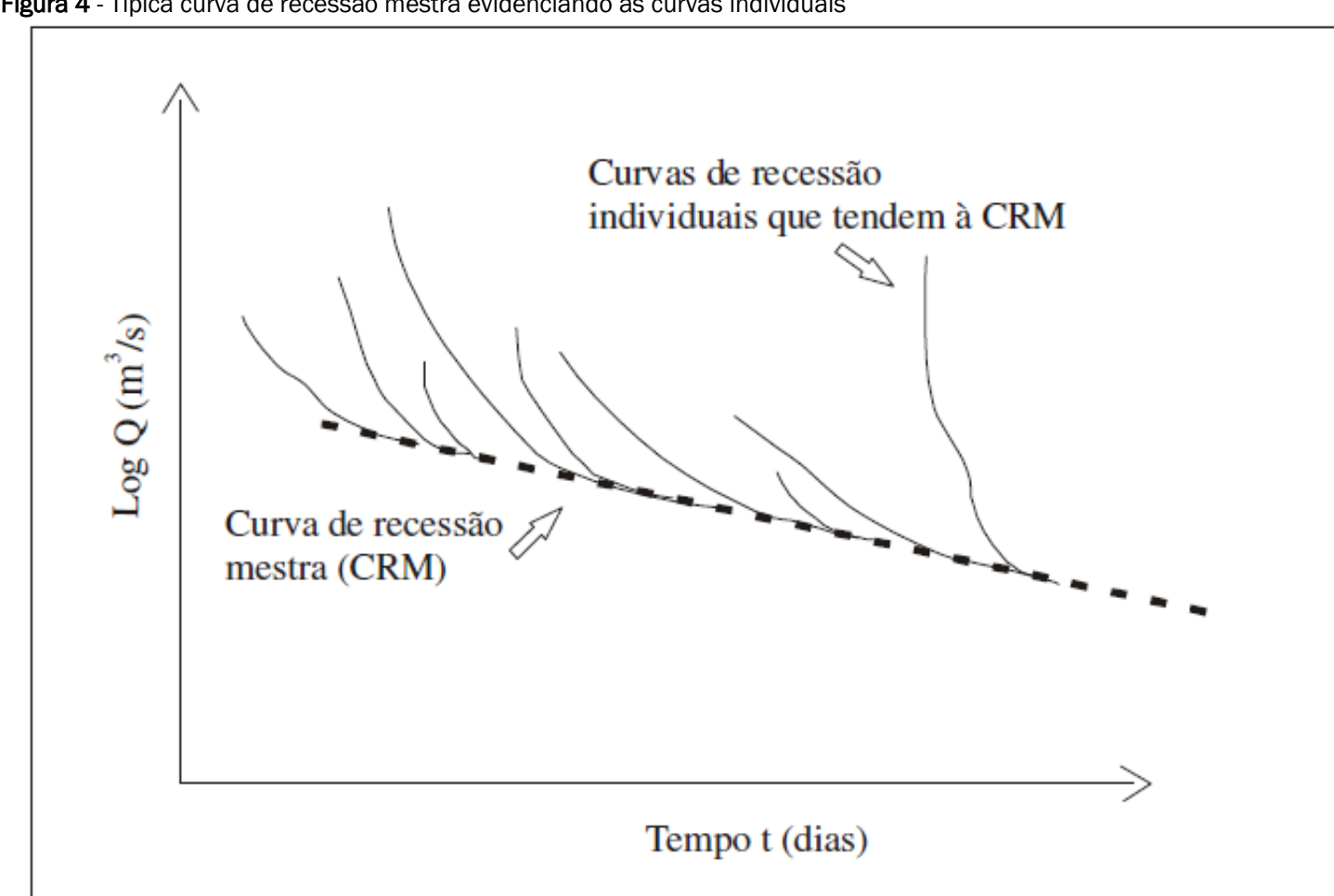

Fonte: Retirado de Costa (2005)

Tal método é adequado ao sistema cárstico pois consiste em analisar todas as curvas de recessão formadas por eventos de chuvas pelo ajuste de uma única reta de tendência (curva de recessão média), porquanto as respostas das vazões aos eventos pluviais em terrenos carbonáticos são quase imediatas e se desfazem rapidamente. 0 método foi aplicado automaticamente, eliminando a subjetividade na separação dos hidrogramas e da recarga. Para tanto, foi adotado o software USGS GW-Toolbox desenvolvido por Barlow et al. (2014) e Bar- low et al. (2017). A partir dos programas internos, HYSEP, RECESS e RORA, calculou-se os hidrogramas e escoamentos; a CRM e a Recarga, respectivamente.

iii) Realização do Balanço Hídrico Climatológico (VELÁSQUEZ et. al., 2018), que resultou nos dados de Evapotranspiração Real (ETR), Excedente Hídrico (EXC), o qual traduz o escoamento superficial e subterrâneo indistintamente, Deficit Hídrico (DEF) e o Armazenamento (ARM). Utilizouse o método de Thornthwaite e Mather (1955), e 
Thornthwaite (1948), para o cálculo da ETR. Os dados de temperatura derivaram da estação metereológica de Sete Lagoas (Código OMM: 8670), 12 km da área, e a pluviometria, de 4 estações dentro da região, todos disponíveis nos sites do Instituto Nacional de Meteorologia - INMET (2017) ou da Agencia Nacional de Águas - ANA (2017). Os cálculos foram tratados nas planilhas eletrônicas de Rolim (1998) por ser aplicável a diferentes tipos de climas com exigência de um número mínimo de dados meteorológicos existentes.

\section{RESULTADOS}

FLUVIOMETRÍA - a vazão aumenta e diminui quase imediata mente aos eventos pluviométricos, denotando baixo armazenamento e alta velocidade dos fluxos na porção superior dos aquíferos, predominando a atuação dos dutos cársticos (Fig. 5). Encontraram-se 3 níveis de vazão (Tab. 2); i) caudalosas, com médias de $0,744 \mathrm{~m}^{3} / \mathrm{s}$ e $0,695 \mathrm{~m}^{3} / \mathrm{s}$, dos sistemas Escrivânia-Gordura e Palmeira-Jaguara, respectivamente; ii) intermediárias, $0,180 \mathrm{~m}^{3} / \mathrm{s}$ e $0,159 \mathrm{~m}^{3} / \mathrm{s}$, do Jaque e Samambaia, respectivamente e iii) baixas, $0,008 \mathrm{~m}^{3} / \mathrm{s}$, do Flor.

Salienta-se o comportamento mais uniforme do córrego samambaia (Fig. 6) devido a regularização da vazão causada por barramento a montante do ponto monitorado 0 córrego Flor é afetado por captações a fio d'água, chegando a secar na estiagem.

Figura 5 - Vazões dos Córregos monitorados e relação com a pluviometria da estação Lagoa Santa (código - 1943049)

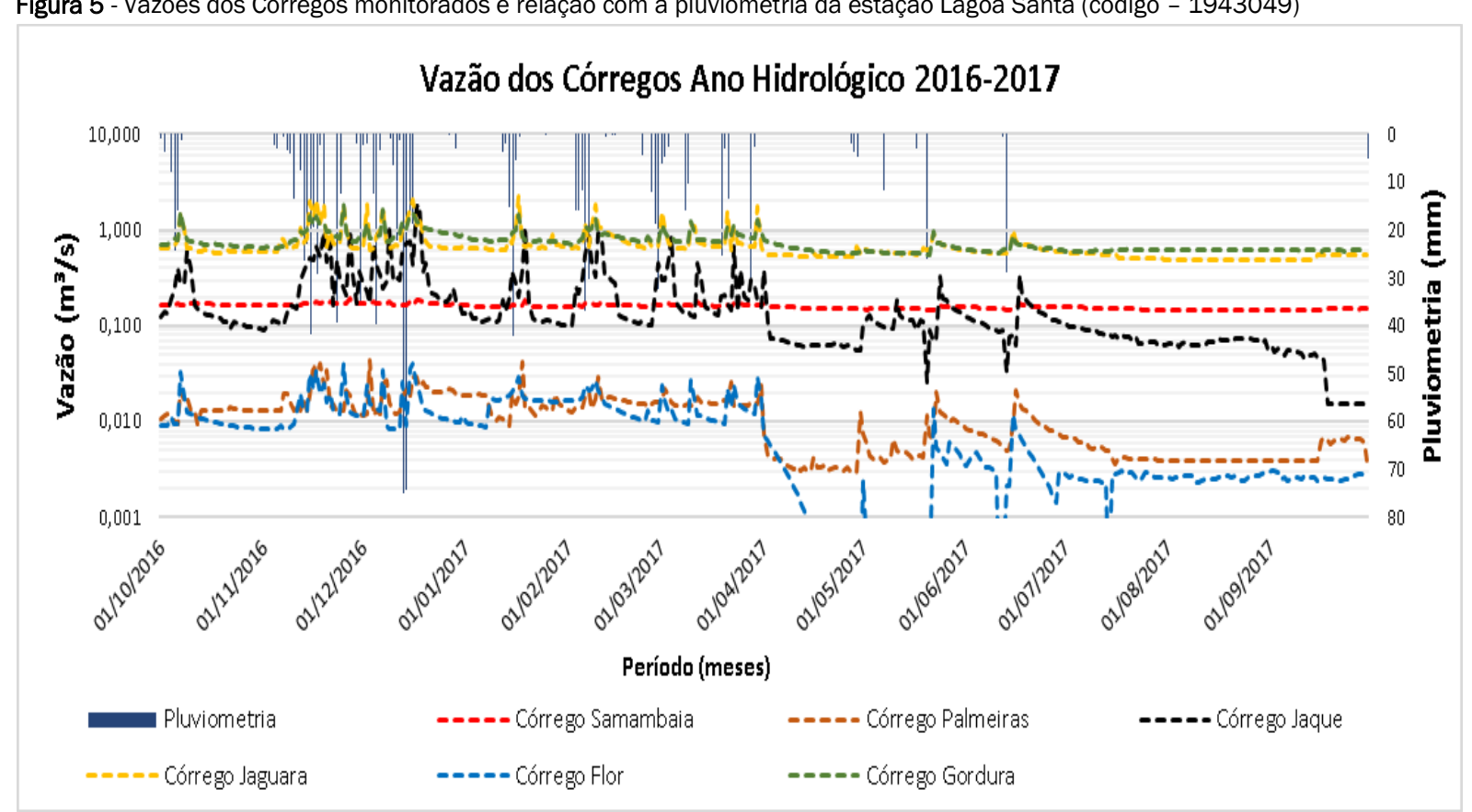

Distinguiram-se 3 níveis de Vazão Específica (Q/s) (Tab. 2), que, com exceção do sistema Pameira-Jaguara, seguiram a mesma tendência de vazão: i) alta $\left(0,0053 \mathrm{~m}^{3} / \mathrm{s} / \mathrm{km}^{2}\right)$; ii) média $\left(0,0031\right.$ a $\left.0,0033 \mathrm{~m}^{3} / \mathrm{s} / \mathrm{km}^{2}\right)$ e iii) baixa $(0,0005$ $\mathrm{m}^{3} / \mathrm{s} / \mathrm{km}^{2}$ ). Destaca-se a bacia Escrivânia-Gordura por apresentar a maior $\mathrm{Q} / \mathrm{s}\left(0,0053 \mathrm{~m}^{3} / \mathrm{s} / \mathrm{Km}^{2}\right)$ mesmo sem aporte externo da surgência. Tal produção seria de $0,0077 \mathrm{~m} 3 / \mathrm{s} / \mathrm{km}^{2}$ se considerado o suposto aporte de água externo ao sistema através da surgência cárstica de 0,23 m³/s (1 da Fig.2) (VELÁSQUEZ et al., 2018), configurando uma vazão específica aparente, Q/sap.

As bacias Samambaia, Palmeira-Jaguara e Jaque possuem valores médios de $\mathrm{Q} / \mathrm{s}\left(0,0033\right.$ a $\left.0,0031 \mathrm{~m}^{3} / \mathrm{s} / \mathrm{km}^{2}\right)$ respectivamente. A produção do Palmeira-Jaguara saltaria para 0,0045 $\mathrm{m}^{3} / \mathrm{s} / \mathrm{Km}^{2}$ se considerado o suposto aporte de água externo ao sistema através de uma surgência denominada Lagoa Bom Jardim de 0,191 $\mathrm{m}^{3} / \mathrm{s}$ (2 da Fig. 2).

A bacia do Flor apresentou uma ínfima Q/s, 0,0005 $\mathrm{m}^{3} / \mathrm{s} / \mathrm{km}^{2}$, explicada pela forte captação no curso, pelo predo- mínio de pelitos e pela presença de feições de recarga (maciços e depressões) apenas na porção baixa da bacia.

A característica das bacias correlatas é a presença de surgências caudalosas de aporte externo drenando para dentro destas bacias, 0,421 m³/s (somatório das nascentes 1 e 2 da Fig. 2); ou para fora do sistema global por meio dessas bacias: 0,171 m³/s (somatório das nascentes 3, 4, 5, 6 e 7 da Fig. 2). Embora exista outras surgências de vazões menores saindo pela margem do Velhas, não se pode medi-las por formarem regiões brejadas com fluxo lento ou por desaguarem diretamente em lagoas sem uma seção adequada.

RECARGA - a análise dos escoamentos mostra um escoamento total de $194 \mathrm{~mm}(19,2 \%$ do total pluviométrico P $1010 \mathrm{~mm}$ ), um índice do fluxo de base (BFI) entre 73\% e 99\% do escoamento total entre as bacias (Tab. 3; Fig. 6), e um escoamento superficial de $18 \mathrm{~mm}(1,8 \%$ da $\mathrm{P}-1010 \mathrm{~mm})$. Tal resultado é bastante coerente com a hidrologia predominantemente subterrânea, com baixa densidade de drenagem superficial (Fig. 2). 
Tabela 2 - Vazão específica do escoamento total das bacias

\begin{tabular}{|c|c|c|c|c|c|}
\hline Bacias & Área $\left(\mathrm{km}^{2}\right)$ & Q.média $\left(\mathrm{m}^{3} / \mathrm{s}\right)$ & DP Q. & $\mathrm{Q} / \mathrm{s}\left(\mathrm{m}^{3} / \mathrm{s} / \mathrm{km}^{2}\right)$ & Q/sap. $\left(\mathrm{m}^{3} / \mathrm{s} / \mathrm{km}^{2}\right)$ \\
\hline Palmeira & 31 & 0,011 & 0,0058 & 0,0004 & - \\
\hline Palmeira/Jaguara* & 156 & 0,695 & 0,151 & 0,0032 & 0,0045 \\
\hline Jaguara & 125 & 0,684 & 0,134 & 0,0055 & - \\
\hline Gordura & 39 & - & -- & -- & 0,0089 \\
\hline Escrivânia & 57 & - & -- & - & 0,0027 \\
\hline Escrivânia/Gordura* & 96 & 0,744 & 0,0014 & 0,0053 & 0,0077 \\
\hline Jaque & 59 & 0,18 & 0,119 & 0,0031 & - \\
\hline Samambaia & 48 & 0,159 & 0,008 & 0,0033 & - \\
\hline Flor & 16 & 0,008 & 0,006 & 0,0005 & - \\
\hline Bom Jesus & 7 & - & - & - & 0,003 \\
\hline Retiro & 10 & - & - & - & 0,0112 \\
\hline Confins & 18 & - & - & - & $* * *$ \\
\hline Margem Rib. da Mata & 38 & - & - & - & 0,001 \\
\hline Margem Velhas & 57 & - & - & - & - \\
\hline Média & 42 & 0,2084 & 0,0546 & 0,0026 & 0,0054 \\
\hline Total & 505 & - & -- & -- & - \\
\hline
\end{tabular}

Tabela 3 - Relação da água subterrânea com escoamento total das bacias.

\begin{tabular}{|c|c|c|c|c|c|}
\hline Bacias & Área $\left(\mathrm{km}^{2}\right)$ & BFI (\%) & $\begin{array}{l}\text { Escoamento Total } \\
(\mathrm{mm})\end{array}$ & $\begin{array}{c}\text { Escoamento Subterrâ- } \\
\text { neo }(\mathrm{mm})\end{array}$ & $\begin{array}{l}\text { Escoamento Superficial } \\
(\mathrm{mm})\end{array}$ \\
\hline Jaque & 59 & 73 & 66 & 48 & 18 \\
\hline Flor & 16 & 79 & 3 & 2 & 0,6 \\
\hline Escrivânia-Gordura & 96 & 89 & $281 *$ & $251 *$ & 30 \\
\hline Gordura & 39 & 94 & $281 *$ & $264 *$ & 17 \\
\hline Palmeira-Jaguara & 156 & 96 & $231 *$ & $221 *$ & 10 \\
\hline Palmeira & 31 & 85 & 4,3 & $3,7 * *$ & 0,6 \\
\hline Jaguara & 125 & 96 & 231 & $221 *$ & 10 \\
\hline Samambaia & 48 & 99 & 59 & 58 & 0,9 \\
\hline Total Ponderado & 375 & 91 & 194 & 176 & 18 \\
\hline
\end{tabular}

* inclui cerca de $30 \%$ de aporte externo; BFl: índice do fluxo de base; **não inclui o aporte externo de surgência cárstica de Bom Jardim, 0 qual é conectado à bacia Jaguara onde é medido no sistema Palmeira-Jaguara; em negrito - entram no cálculo Ponderado.

Figura 6a - Hidrograma da bacia do Flor

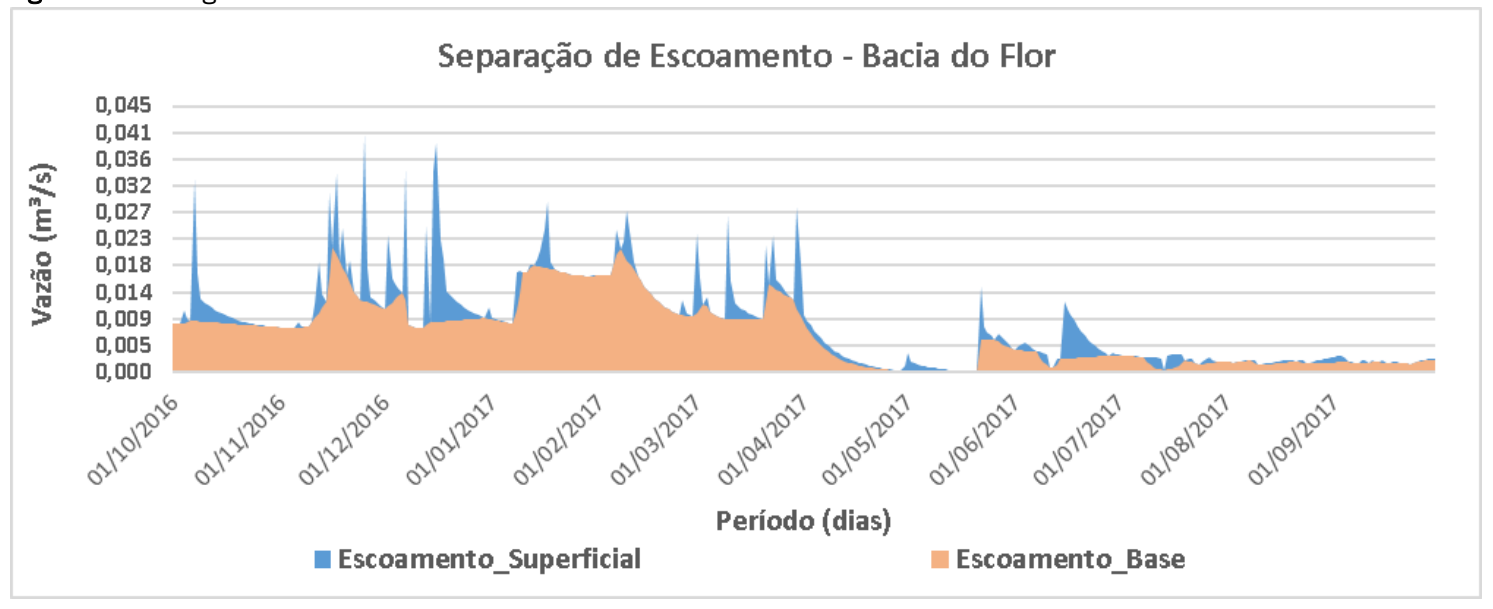


Figura 6b - Hidrograma da bacia do Samambaia

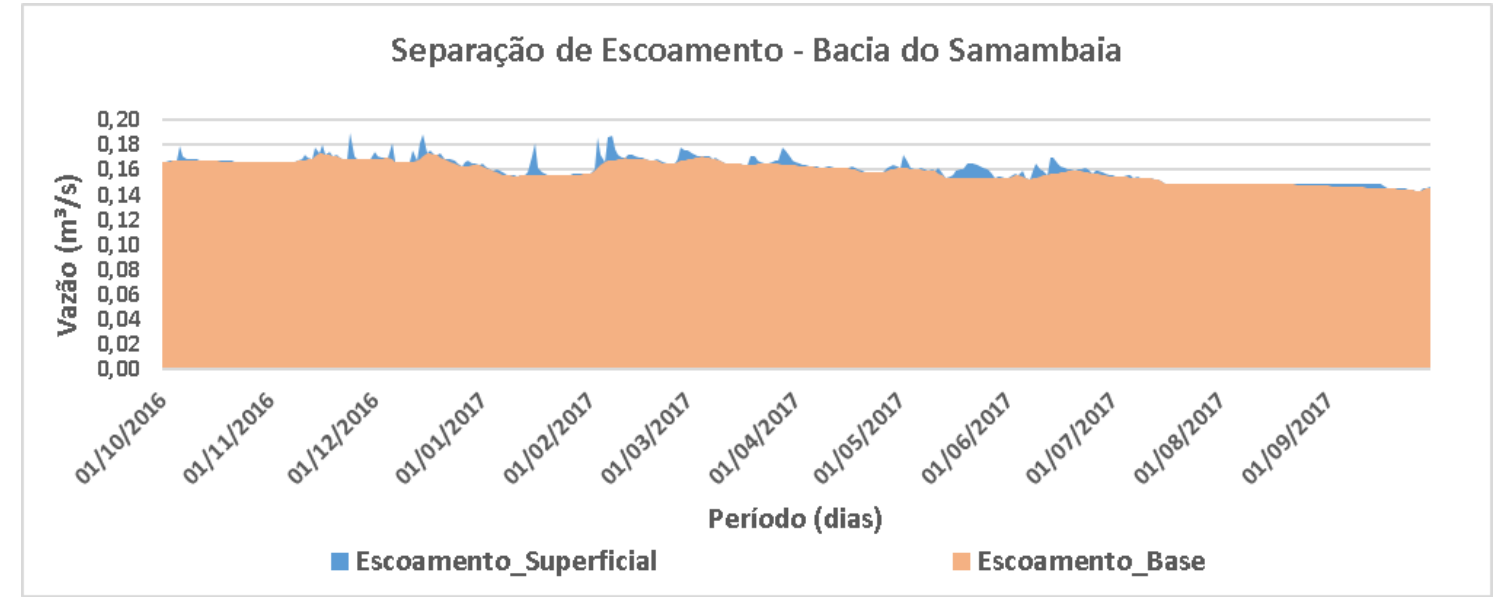

Figura $6 c$ - Hidrograma da bacia do Jaque

Separação de Escoamento - Bacia do Jaque

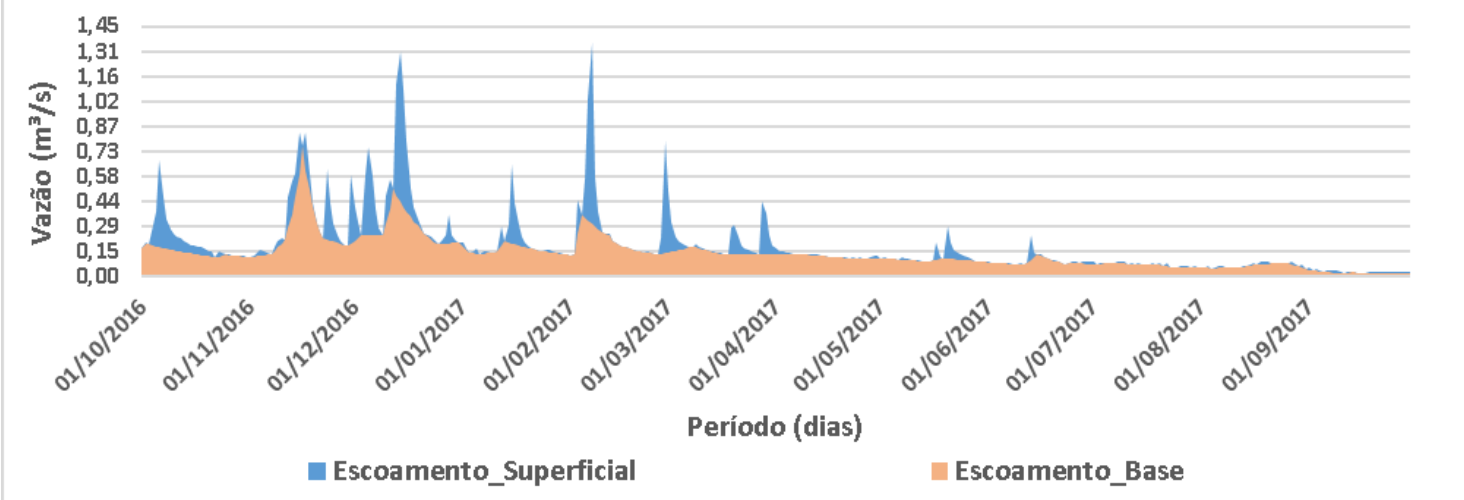

Figura 6d - Hidrograma da bacia do Escrivânia-Gordura

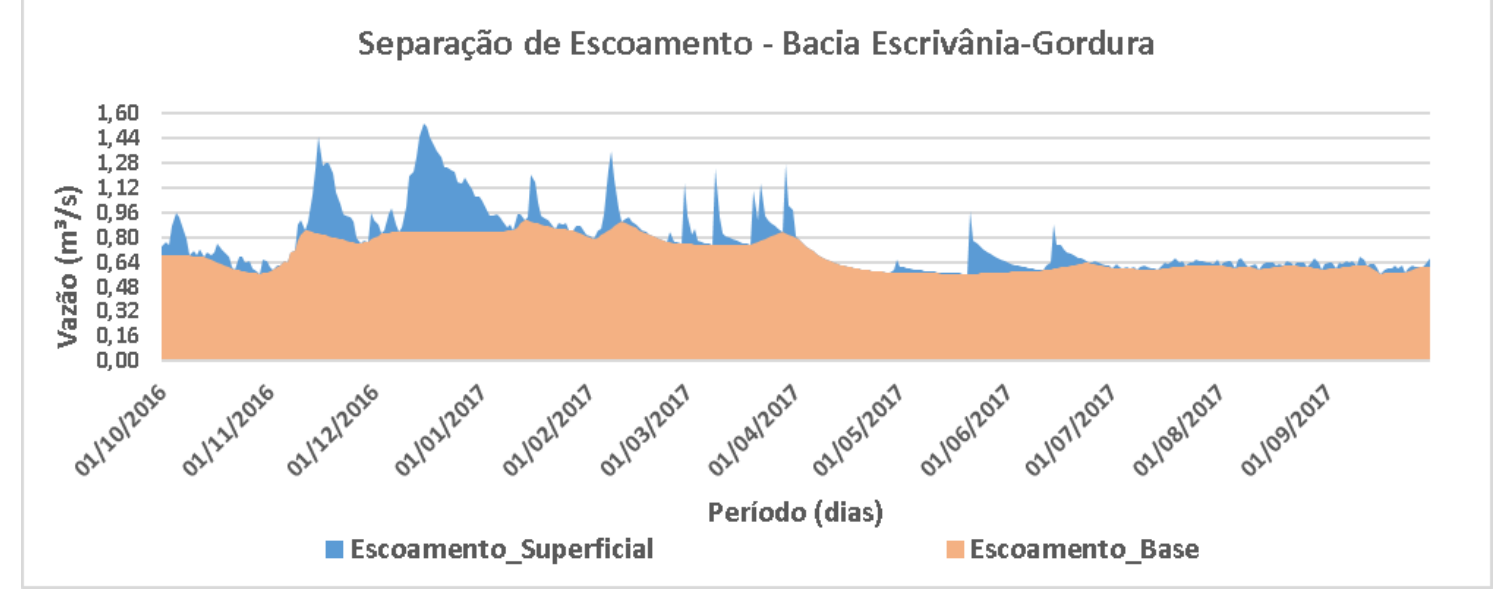


Figura 6e - Hidrograma da bacia do Palmeiras-Jaguara

Figura 6 - Separação dos hidrogramas das bacias pelo programa HYSEP

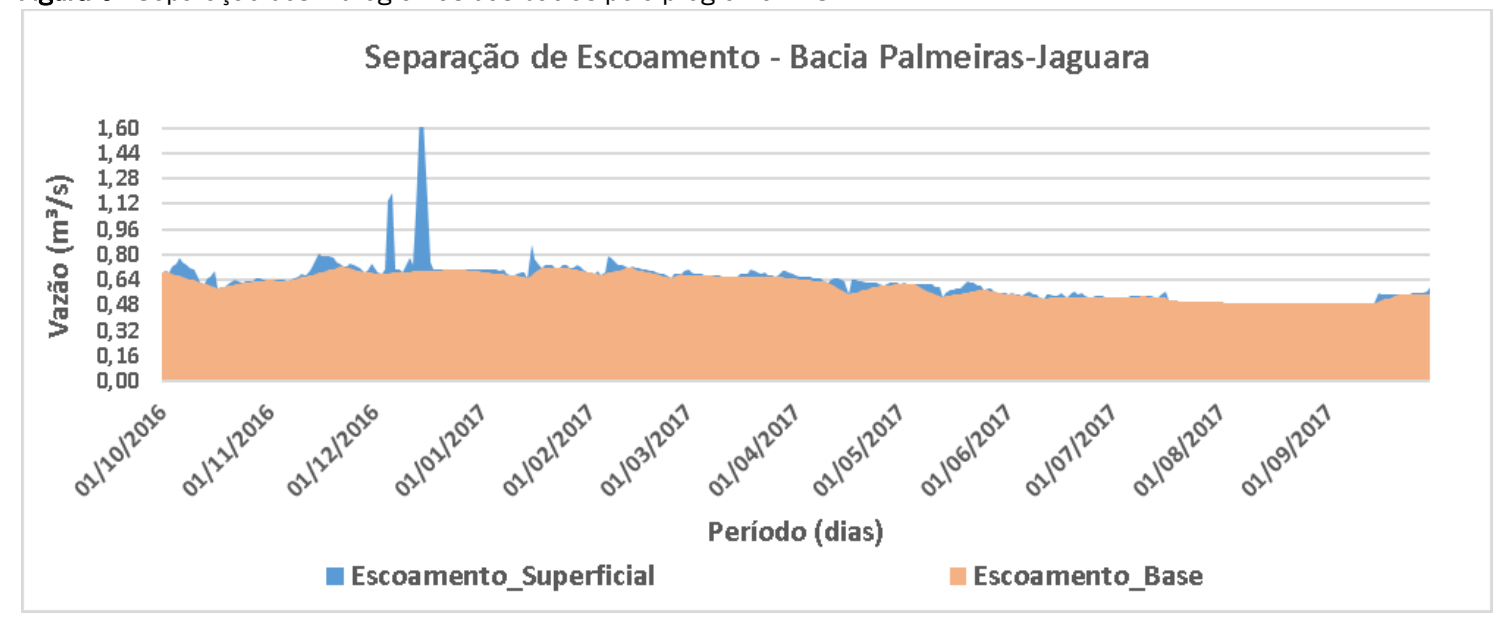

O elevado índice do fluxo de base (BFI) da bacia Palmeira-Jaguara (96\%)_corrobora o elevado grau de carstificação, fato atestado pela presença de grande densidade de sumidouros nesta região mapeados por Silva et al. (1987), que garantem ótimas condições de recarga aquífera, corroborado pelo seu alto valor de escoamento subterrâneo $(221 \mathrm{~mm})$.

O BFI da bacia do Escrivânia-Gordura é de 89\%, com o maior escoamento subterrâneo, de $251 \mathrm{~mm}$ (Tab. 3). 0 maior escoamento superficial $(30 \mathrm{~mm}$ ) se deve ao fato que $59 \%$ desse sistema pertencer a bacia de Escrivánia (Fig. 2), completamente fechada, sem produção de drenagem superficial, com exceção de uma surgência, conforme explicado anteriormente. Esse escoamento superficial cai para $17 \%$ quando desconsidera a bacia de Escrivânia (Tab. 3).

Ressalta-se que ambos os sistemas de bacias citadas possuem um aporte externo mínimo, medido na estiagem, de aproximadamente $30 \%$.

O alto BFI da bacia do Samambaia (99\%) está sendo superes- timado devido à regularização da vazão, conforme já mencionado. Apesar dos elevados valores encontrados em razão da regularização por barramento, os dados desta bacia foram considerados para os cálculos de recarga.

Na bacia do Jaque, o valor mais baixo de BFI (73\%) é coerente com a litologia metapelítica predominante, onde as drenagens percorrem.

Na bacia Flor, o escoamento subterrâneo de $2 \mathrm{~mm}$ para um escoamento total de $3 \mathrm{~mm}$, evidencia as intensas retiradas por poços tubulares e por captações a fio d'água, chegando a secar o córrego, não representando o comportamento natural da bacia.

O número das pequenas recessões em resposta aos eventos pluviométricos identificados variou de 20 a 23, e os índices de recessão (K) obtidos pelo programa RECESS foi de 19 a 240 dias/ciclo log, cujas influências sobre esses valores estão apontadas na Tabela 4.

Tabela 4 - Cálculo dos Índices de recessão das bacias

\begin{tabular}{lccl}
\hline \multicolumn{1}{c}{ Bacias } & $\begin{array}{c}\mathbf{N}^{\circ} \text { de Eventos de Reces- } \\
\text { são }\end{array}$ & $\begin{array}{c}\text { Indice de Recessão }-\mathrm{K} \\
\text { (dias/ciclo log) }\end{array}$ & Principais influências sobre K \\
\hline Palmeira-Jaguara & 23 & 178 & Alto armazenamento \\
Escrivânia-Gordura & 20 & 68 & Alta velocidade de escoamento \\
Samambaia & 21 & 240 & Efeito do barramento artificial \\
Flor & 20 & 19 & Baixo armazenamento \\
Jaque & 22 & 20 & Baixo armazenamento \\
\hline
\end{tabular}

A partir dos dados de recessão e escoamento básico, calculouse os valores de recarga líquida anual pelo programa RORA (Tab. 5), resultando em 12 a $164 \mathrm{~mm}$ para a recarga, isto é, sem o aporte externo de cerca de $30 \%$ em duas delas. Nas bacias monitoradas, a recarga foi de $108 \mathrm{~mm}$ ou $11 \%$ da precipitação, não incorporando os volumes descarregados para fora do sistema. Esse valor mínimo será admitido nas demais bacias não monitoradas. 
Tabela 5 - Recarga nas bacias monitoradas em relação à pluviometria de $1010 \mathrm{~mm}$.

\begin{tabular}{|c|c|c|c|c|c|}
\hline Bacias & $\begin{array}{l}\text { Área } \\
\left(\mathrm{km}^{2}\right)\end{array}$ & $\begin{array}{c}\text { Recarga Bruta } \\
(\mathrm{mm})\end{array}$ & $\begin{array}{c}\text { Rec. Bruta/Pluv. } \\
(\%)\end{array}$ & $\begin{array}{c}\text { Recarga Líquida } \\
(\mathrm{mm})\end{array}$ & $\begin{array}{c}\text { Rec Líq./Pluv. } \\
(\%)\end{array}$ \\
\hline Bacia do Flor & 16 & 12 & 1,2 & 12 & 1,2 \\
\hline Escrivânia-Gordura & 96 & $234 *$ & 21,3 & $164 * *$ & 16,2 \\
\hline Gordura & 39 & $596 *$ & 59 & $179 * *$ & 18,0 \\
\hline Palmeira-jaguara & 156 & $140 *$ & 13,5 & $98 * *$ & 9,7 \\
\hline Samambaia & 48 & 104 & 10,4 & 104 & 10,4 \\
\hline Jaque & 59 & 72 & 7,1 & 72 & 7,1 \\
\hline Média & - & 113 & 10,6 & 90 & 8,9 \\
\hline Total Ponderado (exceto Gordura) & 375 & 143 & 12,2 & 108 & 10,7 \\
\hline
\end{tabular}

* com aporte externo; ** sem o aporte externo

A bacia do Escrivânia-Gordura destacou-se pelo maior percentual de recarga, $16,2 \%$ da precipitação (164 $\mathrm{mm}$ ), seguida do Samambaia e Palmeira-Jaguara, com 10,4\% (104 mm) e 9,7\% (98 $\mathrm{mm})$, respectivamente. A bacia do Jaque obteve o menor valor desse percentual, 7,1\% (72 mm), devido à cobertura pelítica. Já a bacia do Flor apresentou valores insignificantes, $1,2 \%$ (12 mm), por se apresentar extremamente antropizada.
BALANÇO DE MASSA - a retirada de água dos poços tubulares e dos córregos foi avaliada. Velásquez et al. (2018) realizou um cadastro de 380 poços, os quais possuíam uma média de operação de $12 \mathrm{~h} / \mathrm{d}$. Para as captações superficiais, foi admitida uma retirada de $8 \mathrm{~h} / \mathrm{d}$. A partir destes dados, estimou-se a retirada de água por bacia (Tab. 6).

Tabela 6 - Balanço de massa com as retiradas por poços e captações a fio d'água

\begin{tabular}{lccccccc}
\hline \multicolumn{1}{c}{ Bacias } & $\begin{array}{c}\text { Área } \\
\left(\mathrm{km}^{2}\right)\end{array}$ & $\begin{array}{c}\text { Núm. Po- } \\
\text { ços }\end{array}$ & $\begin{array}{c}\text { Q Mediana } \\
\text { poços }\left(\mathrm{m}^{3} / \mathrm{h}\right)\end{array}$ & $\begin{array}{c}\text { Q Total poços } \\
\left(\mathrm{m}^{3} / \mathrm{h}\right)\end{array}$ & $\begin{array}{c}\text { Q superficiais } \\
(\mathrm{m} 3 / \mathrm{h})\end{array}$ & $\begin{array}{c}\text { Captações } \\
\text { poços } \\
(\mathrm{mm} / \mathrm{ano})\end{array}$ & $\begin{array}{c}\text { Captações } \\
\text { córregos } \\
(\mathrm{mm})\end{array}$ \\
\hline Palmeira & 31 & 29 & 9,2 & 357,2 & -- & 50 & - \\
Flor & 16 & 2 & 5,2 & 10,4 & -- & 3 & - \\
Jaque & 59 & 74 & 9,2 & 902,3 & -- & 67 & -- \\
Samambaia & 48 & 22 & 10 & 398,1 & -- & 36 & - \\
Palmeira/Jaguara* & 156 & 80 & 9,2 & 921 & -- & 26 & -- \\
Jaguara & 125 & 51 & 10 & 583,1 & -- & 20 & - \\
Escrivânia/Gordura* & 96 & 24 & 12,5 & 251,7 & 75 & 11 & 2 \\
Bom Jesus & 7 & 5 & 4,8 & 26,5 & -- & 17 & - \\
Retiro & 10 & 19 & 10,7 & 734,1 & -- & 322 & - \\
Confins & 18 & 35 & 10 & 849,7 & 73 & 207 & 12 \\
Margem Rib. da Mata & 38 & 79 & 9,3 & 1727,9 & 194 & 199 & 15 \\
Margem Velhas & 57 & 40 & 9,3 & 1015,6 & 43 & 78 & 2 \\
Média & 46 & 35 & 9,1 & 623,32 & 96 & 92 & 31 \\
Total área global & 505 & 380 & -- & 6856,5 & 385 & 119 & 2 \\
\hline
\end{tabular}

*Os dados da bacia conjunta, não foi contemplado na média e no total para evitar dupla contagem; em negrito - bacias não monitoradas.

As bacias não monitoradas apresentam retiradas consideravelmente maiores por poços tubulares do que as monitoradas (Tab. 6), graças à maior densidade de poços junto aos centros urbanos na metade sul da área.

A Tabela 7 sintetiza os valores do balanço entre a recarga líquida e a saída de água por bombeamento e captação superficial. Atenta-se para os déficits importantes (-214 mm a -106 $\mathrm{mm}$ ) verificados nas bacias de maior extração, Retiro, Confins e Margem Ribeirão da Mata. As demais tiveram os superávits: alto, de 150 mm (Escrivânia-Gordura), médio, de 68 mm, 72 mm e 91 mm (Samambaia, Palmeira-Jaguara, Bom Jesus, respectivamente) e baixo, de $4 \mathrm{~mm}, 9 \mathrm{~mm}$ e $28 \mathrm{~mm}$ (Jaque, Flor e Margem Velhas, respectivamente). No geral, a área registrou um déficit de $-13 \mathrm{~mm}$, influenciado pelas bacias da região sul.
No balanço de massa (recarga líquida) apresentado na tabela 7 , foram consideradas como entradas a precipitação de 1010 mm e as duas surgências cársticas 1 e 2 (Fig. 7 e Tab. 8), com valores de $828 \mathrm{~m}^{3} / \mathrm{h}$ e $691 \mathrm{~m}^{3} / \mathrm{h}$ respectivamente, somando $1519 \mathrm{~m}^{3} / \mathrm{h}$ ou $26 \mathrm{~mm}$ para a área. As saídas contabilizadas são representadas pela extração dos poços tubulares, $6.856,5 \mathrm{~m}^{3} / \mathrm{h}$ ou $119 \mathrm{~mm}$ (Fig. 7 e Tab. 8); as captações superficiais, totalizando $385 \mathrm{~m}^{3} / \mathrm{h}$ ou $2 \mathrm{~mm}$ (Fig.7 e Tab.8); e as descargas para o Ribeirão da Mata, que descarregam através das surgências $3\left(76 \mathrm{~m}^{3} / \mathrm{h}\right) ; 4$ (25 m³/h); 5 (15 m³/h); 6 (122 $\mathrm{m}^{3} / \mathrm{h}$ ) e $7\left(404 \mathrm{~m}^{3} / \mathrm{h}\right.$ ) (Fig. 7 e Tab. 8), totalizando $642 \mathrm{~m}^{3} / \mathrm{h}$ ou $11 \mathrm{~mm}$ para a área total.

A Tabela 8 e Figura 7 resume o balanço hídrico com os quantitativos das entradas e saídas. 
Tabela 7 - Recarga líquida, saídas de água das bacias e balanço hídrico

\begin{tabular}{|c|c|c|c|c|c|c|}
\hline Bacias & $\begin{array}{l}\text { Área } \\
\left(\mathrm{km}^{2}\right)\end{array}$ & $\begin{array}{l}\text { Recarga Líquida } \\
\text { pluvial (mm/ano) }\end{array}$ & $\begin{array}{c}\text { Vol. recarga Lí- } \\
\text { quida pluvial } \\
\left(\mathrm{m}^{3}\right) \\
\end{array}$ & $\begin{array}{l}\text { Saída poços } \\
\text { (mm/ano) }\end{array}$ & $\begin{array}{c}\text { Saída captações } \\
\text { em córregos } \\
(\mathrm{mm})\end{array}$ & $\begin{array}{l}\text { Balanço Entras- } \\
\text { Saídas }(\mathrm{mm})\end{array}$ \\
\hline Palmeira & 31 & -- & -- & -- & -- & -- \\
\hline Palmeira/Jaguara* & 156 & 98 & 15.288 .000 & 26 & - & 72 \\
\hline Gordura & 39 & - & - & - & -- & - \\
\hline Escrivânia/Gordura* & 96 & 164 & 15.744 .000 & 12 & 2 & 150 \\
\hline Flor & 16 & 12 & 192.000 & 3 & -- & 9 \\
\hline Jaque & 59 & 71 & 4.189 .000 & 67 & - & 4 \\
\hline Samambaia & 48 & 104 & 4.992 .000 & 36 & - & 68 \\
\hline Jaguara & 125 & - & -- & -- & - & -- \\
\hline Escrivânia & 57 & -- & -- & -- & - & -- \\
\hline Bom Jesus & 7 & $108 * *$ & 756.000 & 17 & -- & 91 \\
\hline Retiro & 10 & $108 * *$ & 1.080 .000 & 322 & - & -214 \\
\hline Confins & 18 & $108 * *$ & 1.944 .000 & 207 & 12 & -111 \\
\hline Margem Rib. da Mata & 38 & $108 * *$ & 4.104 .000 & 199 & 15 & -106 \\
\hline Margem Velhas & 57 & $108 * *$ & 6.156 .000 & 78 & 2 & 28 \\
\hline Média & 42 & & 5.445 .000 & 104 & 30 & $-0,9$ \\
\hline Total área global & 505 & 108 & 54.445 .000 & 119 & 2 & -13 \\
\hline \multicolumn{7}{|c|}{$\begin{array}{l}\text { *Os dados da bacia conjunta, não foram contemplados na média e no total para evitar dupla contagem; ** valor adotado da recarga líquida } \\
\text { das bacias monitoradas da Tabela } 5\end{array}$} \\
\hline & & \multicolumn{2}{|c|}{ Entradas (mm) } & las $(\mathrm{mm})$ & \multicolumn{2}{|c|}{ Balanço Hídrico (mm) } \\
\hline \multicolumn{2}{|l|}{ Pluviometria } & \multicolumn{2}{|c|}{1010} & -- & \multicolumn{2}{|l|}{-} \\
\hline \multicolumn{2}{|c|}{ Surgências cársticas 1 e 2} & \multicolumn{2}{|l|}{26} & -- & \multicolumn{2}{|l|}{--} \\
\hline \multicolumn{2}{|c|}{ Surgências cársticas 3 a 7} & \multicolumn{2}{|l|}{--} & -11 & \multicolumn{2}{|l|}{-} \\
\hline \multicolumn{2}{|c|}{ Captações Poços Tubulares } & \multicolumn{2}{|l|}{-} & -119 & \multicolumn{2}{|l|}{--} \\
\hline \multicolumn{2}{|l|}{ Captações superficias } & \multicolumn{2}{|l|}{-} & -2 & \multicolumn{2}{|l|}{--} \\
\hline \multicolumn{2}{|c|}{ Escoamento Total (sup + subt) } & \multicolumn{2}{|l|}{--} & -194 & \multicolumn{2}{|l|}{-} \\
\hline \multicolumn{2}{|c|}{ Total sob condições antropizadas } & \multicolumn{2}{|c|}{1036} & -326 & \multicolumn{2}{|c|}{710} \\
\hline \multicolumn{2}{|c|}{ Total sob condições naturais } & \multicolumn{2}{|c|}{1036} & -205 & \multicolumn{2}{|c|}{831} \\
\hline
\end{tabular}

Num cenário sob condições naturais, em que as saídas de origem antrópica não ocorrem, a descarga bruta natural total é de $194 \mathrm{~mm}$ (19,2\% da $\mathrm{P}$ - $1010 \mathrm{~mm})$, na proporção de 1,1/1,0 (escoamento total/escoamento subterrâneo). Entretanto, desse montante total, devem ser subtraídos $26 \mathrm{~mm}$ oriundos das surgências caudalosas 1 e 2 (Fig. 7), resultando num escoamento total natural de $168 \mathrm{~mm}$. Aplicando-se a proporção acima, o escoamento subterrâneo seria corrigido para $152 \mathrm{~mm}$ e o superficial para $16 \mathrm{~mm}$. Esse escoamento total (168 mm) ficou aquém do estimado pelo balanço climático (260 mm) em $92 \mathrm{~mm}$. Esse fato pode ser adotado como ver- dadeiro, visto que a prática de captações a fio d'água e não outorgados são frequentes na região.

A recarga aquífera foi avaliada em $108 \mathrm{~mm}$ (11\% da $\mathrm{P}-1010$ $\mathrm{mm})$, Tabela 5, porém, os escoamentos das descargas naturais 3 a 7 (11 mm, Tab. 8) são uma parcela dessa recarga, que, ajustada, corresponde a $119 \mathrm{~mm}$ (12\% da P - $1010 \mathrm{~mm})$. Tal valor de recarga, representando 7,4 vezes o valor do escoamento superficial corrobora as excelentes condições de infiltração, como os abundantes maciços fraturados, sumidouros e dolinas. 
Figura 7 - Croqui esquemático do balanço hídrico global com destaque para nascentes de entradas e de saídas de água externas ao sistema estudado

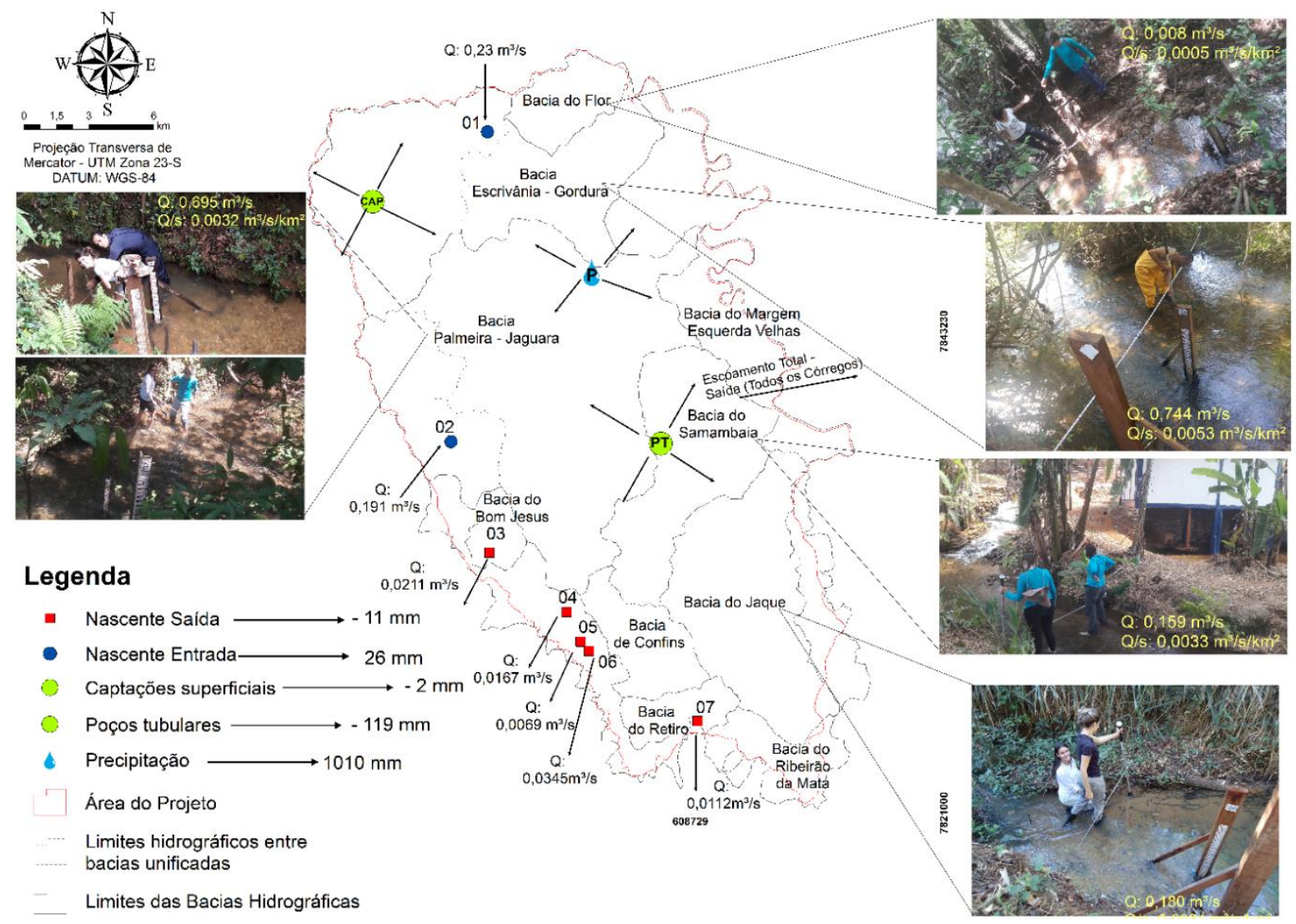

Do escoamento subterrâneo, há ainda um excedente de 33 $\mathrm{mm}$ que pode ser total ou parcialmente incorporado à recarga aquífera, pois diversas outras surgências na margem do rio das Velhas não puderam ser medidas. Considera-se ainda recargas de maciços calcários para zonas aquíferas mais profundas de baixa conexão com a rede de circulação superior que facilita as descargas monitoradas.

Assim, a recarga encontrada, deve ser considerada como um valor mínimo.

A pluviometria de Thiessen, $1033 \mathrm{~mm}$ (VELÁSQUEZ et. al., 2018), obtida a partir de dados mensais de precipitação e temperatura resultou que as estações de Lagoa Santa e Pedro Leopoldo exercem maior influência, 50\% e 25\% na área, respectivamente (Fig. 8).
Assim, o balanço hídrico climático de Thornthwaite-Mather (1955) foi realizado para um total pluviométrico de $1010 \mathrm{~mm}$ na estação Lagoa Santa, uma capacidade de campo de 250 mm. Obtiveram-se para toda a área: ETR de 750 mm (74\%), ETP de 895 mm EXC de 260 mm (26\%), DEF de 145 mm, valores muito próximos aos históricos de 1961 a 1990 de Viana (1998), considerando a pluviometria de $1287 \mathrm{~mm}$, ETR de 996 mm (77\%), EXC de 291 mm (22,6\%) e DEF de 99 mm (8\%).

Ainda num cenário sob condições naturais, o escoamento total seria de $205 \mathrm{~mm}$ (Tab. 8), resultando um superávit de 831 $\mathrm{mm}$, baixando para $710 \mathrm{~mm}$ se as retiradas forem incorporadas. Assim, O ETR do balanço climático estimado de $750 \mathrm{~mm}$ é coerente com os valores de superávit encontrados no monitoramento. 
Figura 8 - Mapa de precipitação de Thiessen evidenciando a influência da estação de Lagoa Santa e Pedro Leopoldo

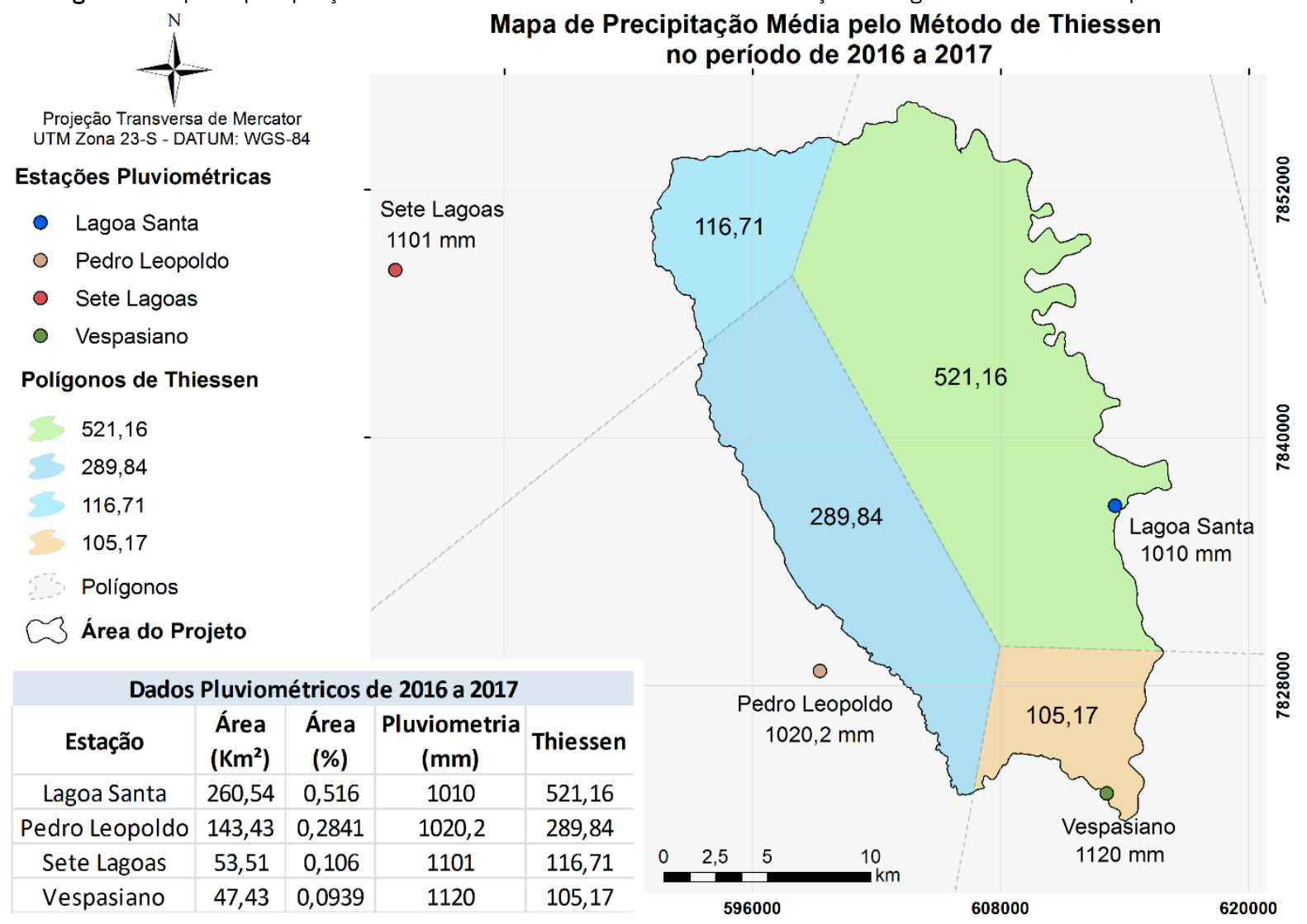

Fonte: Adaptado de Velásquez et. al. (2018)

\section{CONCLUSÕES}

Os métodos empregados para o monitoramento e análise dos dados hidrológicos resultaram em quantitativos coerentes com o sistema hidrogeológico cárstico local. Permitiram identificar as variações de produtividade e de recarga entre as bacias em função das suas características hidrogeológicas e seu grau de antropização.

A recarga obtida de $119 \mathrm{~mm}$ (12\% da pluviometria) representou 7,4 vezes o valor do escoamento superficial resultado das excelentes condições de infiltração, como os abundantes maciços fraturados, sumidouros e dolinas, o que é corroborado pela escassa rede de drenagem superficial e pelo índice de 91\% do escoamento subterrâneo sobre o superficial.

As explotações em locais de maior densidade de poços tubulares colocaram em evidência 3 das 10 bacias envolvidas no estudo, que já mostram déficits em relação a recarga aplicada. Ademais, a recarga de $119 \mathrm{~mm}$ já equivale à água que está sendo bombeada. $\mathrm{E}$ as retiradas em córregos revelam elevado grau de antropização em uma bacia, com ínfima capacidade específica.

Esse estudo ainda requer ampliação de pontos de controle de entradas e saídas, contudo, o elevando grau de coerência dos resultados, confirmam a necessidade de semelhante controle em sistemas hidrogeológicos cársticos.

\section{AGRADECIMENTOS}

Ao Centro Nacional de Pesquisa e Conservação de Cavernas
(CECAV/ICMBio) pelo financiamento, Proc. FUNDEP/GERDAU/UFMG No 22.317, Instituto de Geociências da Universidade Federal de Minas Gerais (IGC-UFMG).

\section{REFERÊNCIAS}

ALBUQUERQUE A. C. S. Estimativa de recarga da bacia do rio das fêmeas através de métodos manuais e automáticos. Dissertação (Mestrado, em Ciências Florestais) - Universidade de Brasília, 2009, 101p.

ANA - Agência Nacional de Águas. Disponível em: http://mapas-hidro.ana.gov.br/Usuario/Esta-

cao.aspx?est=193343540. Acesso em: 10 mar. 2017.

AULER A. Hydrogeological and Hydrochemical Characterization of the Matozinhos-Pedro Leopoldo Karst, Brazil. 1994. $110 \mathrm{f}$. Msc Thesis - Faculty of the Department of Geography and Geology, Western Kentucky University, Bowling Green, 1994.

BARLOW, P.M., CUNNINGHAM, W.L., ZHAI, TONG, and GRAY, MARK, U.S. Geological Survey Groundwater Toolbox, a graphical and mapping interface for analysis of hydrologic data (version 1.0): User guide for estimation of base flow, runoff, and groundwater recharge from streamflow data: U.S. Geological Survey Techniques and Methods, book 3, chap. B10, 2014, $27 \mathrm{p}$.

BARLOW, P.M., CUNNINGHAM, W.L., ZHAI, TONG, and GRAY, MARK, U.S. Geological Survey Groundwater Toolbox version 1.3.1, a graphical and mapping interface for analysis of hydro 
logic data: U.S. Geological Survey Software Release, 26 May 2017.

COSTA F. M. Análise por métodos hidrológicos e hidrogeoquímico de fatores condicionantes do potencial hídrico de bacias hidrográficas: estudo de caso no quadrilátero ferrífero - MG. Dissertação (Mestrado em Ciências Florestais) - Universidade Federal de Ouro Preto, 2005, 147p.

FILHO, K. Z., SILVA, R. M., PORTO, R. L. L. Medição de vazão e curva chave. Escola Politécnica da Universidade de São Paulo - Departamento de Engenharia Hidráulica e Sanitária. PHD 307 Hidrologia aplicada, 2001, 48p.

GALVÃO, P., HIRATA, R., CORDEIRO, A., BARBATI, D. \& PEÑHARANDA, J. Geologic conceptual model of the municipality of Sete Lagoas (MG, Brazil) and the surroundings. Anais da Academia Brasileira de Ciências, v. 88, n. 1, p. 35-53, 2016.

GOLDSCHEIDER, N.; DREW D. Methods in Karst Hydrogeology. International Contributions to Hydrogeology, 26, London, TayIor \& Francis, 2007, 264p.

INMET - Instituto Nacional de Meteorologia. Disponível em: http://www.inmet.gov.br/portal/index.php?r=estacoes/estac oesautomaticas. Acesso em: 10 mar. 2017.

PESSOA, P. F. P. 2005. Hidrogeologia do aquífero cárstico coberto de Lagoa Santa, MG. Tese (Doutorado) - Universidade Federal de Minas Gerais, Belo Horizonte, 2005, 375p.

PISCOYA, R. C. C. C.; LOPES, W. T. A.; LEMOS, G. M.; SILVA, L. S.; SILVA, M. C. A. M. Análise de consistência de dados fluviométricos de estações de monitoramento da ANA localizadas nas sub-bacias hidrográficas 10 (rios Solimões, Javari e Itaquaí) e 11 (rios Solimões, Içá e Jandiatuba). In: SIMPÓSIO BRASILEIRO DE RECURSOS HÍDRICOS, 20, 2013, Bento Gonçalves, RS. Anais... ABRH - Associação Brasileira de Recursos Hídricos, 2013.

RIBEIRO, J.H.; TULLER, M.P.; FILHO, A.D.; PADILHA, A.V.; CÓRDOBA, C.V. Projeto VIDA: mapeamento geológico, região de Sete Lagoas, Pedro Leopoldo, Matozinhos, Lagoa Santa, Ves- pasiano, Campim Branco, Prudente de Morais, Confins e Funilândia, Minas Gerais - relatório final, escala 1:50.000. 2. ed. Belo Horizonte: CPRM, 2003, 54p.

ROLIM, G.S.; SENTELHAS, P.C.; BARBIERI, V. Planilhas no ambiente EXCEL para os cálculos de balanços hídricos: normal, sequencial, de cultura e de produtividade real e potencial. Revista Brasileira de Agrometeorologia, Santa Maria, v.6, p.133137, 1998.

RUTLEDGE, A. T., DANIEL, C. C. Testing an automated method to estimate ground-water recharcge from sreamflow records. Ground Water. v. 32, n. 2, p. 180-189, 1994.

SILVA, A. B.; MOREIRA, C. V. R.; CESAR, F. M.; AULER, A. Estudo da dinâmica dos recursos hídricos da região cárstica dos municipios de Lagoa Santa, Pedro Leopoldo e Matozinhos. Unpublished technical report, CETEC, 1987, p.32.

THORNTHWAITE, C.W. An approach toward a rational classification of climate. Geogr. Rev, v. 38, p.55-94, 1948.

THORNTHWAITE, C.W.; MATHER, J.R. The water balance. Publications in Climatology. New Jersey: Drexel Institute of Technology, 1955, 104p.

TUCCI, C. E. M. et al. Hidrologia ciência e aplicação. 2. ed. Rio Grande do Sul: Editora da Universidade Federal do Rio Grande do Sul, 2002, 943 pp.

VELÁSQUEZ, L.N.M.; (Org.) $3^{\circ}$ Relatório parcial de 04 do projeto de adequação e implantação de uma rede de monitoramento de águas subterrâneas em áreas com cavidades cársticas da Bacia do Rio São Francisco aplicado à área piloto da APA Carste de Lagoa Santa, Minas Gerais. Belo Horizonte, 2018. 142p.(inédito)

VIANA, H.S.; KOHLER, H.C.; TAVARES, V.P. (Org.). APA Carste de Lagoa Santa: meio físico - Volume I. Belo Horizonte: IBAMA/CPRM, 1998, 301p.

WHITE, W.B. Karst hydrology: recent developments and open questions. Engineering Geology, v. 65, p. 85-105, 2002. 